\title{
Study of Degradation of Phenol in Waste Water Sample via Advanced Oxidation Technology
}

\author{
Junsen $\mathrm{Wu}^{1, \mathrm{a}^{*}}$, Ruibao Jia ${ }^{2, \mathrm{~b}}$, Chenchen Liu${ }^{1, \mathrm{c}}$ and Hongtu Wang ${ }^{1, \mathrm{~d}}$ \\ ${ }^{1}$ Municipal and environmental engineering institute, Shandong Jianzhu University, China \\ 2 Jinan water supply and drainage monitoring center, China \\ aJunsenwu@163.com, b18764466725@163.com, \\ chenchening@163.com, ${ }^{\mathrm{d}} 1440443406 @ q q . c o m$
}

Keywords: Ultrasound (US); $\mathrm{H}_{2} \mathrm{O}_{2}$; Fenton reagent; Phenol

Abstract. The article study the effect and different conditions of degradation phenol in waster water samples via Ultrasound (US), $\mathrm{H}_{2} \mathrm{O}_{2}$, fenton reagents oxidation technology. Experiments show that the degradation of phenol only use of single US or $\mathrm{H}_{2} \mathrm{O}_{2}$ treatment is not ideal while US used in conjunction with Fenton degradation of Phenol is best, and the acidic conditions favor the degradation of phenol. In this experiment, the best ratio of $\mathrm{FeSO}_{4} .7 \mathrm{H}_{2} \mathrm{O}$ and $\mathrm{H}_{2} \mathrm{O}_{2}$ is 1:20 in Fenton reagent.

\section{Introduction}

Advanced oxidation is the oxidation of hydroxyl radicals in the process of water treatment. Compared with other conventional water treatment methods, advanced oxidation has the following characteristics, Produce a large number of very reactive hydroxyl radicals. $\mathrm{OH}$, does not produce secondary pollution, the reaction speed is very fast, and can meet the requirements of the processing in a very short time. In this experiment, ultrasonic (US), $\mathrm{H}_{2} \mathrm{O}_{2}$, Fenton reagent and other oxidation techniques were used to deal with the water samples. Determine their optimum operating parameters, and to provide a theoretical basis for the application of advanced oxidation technology in practical engineering.

\section{Materials and reagents}

Reagents and instruments. Phenol, $\mathrm{H}_{2} \mathrm{O}_{2}(30 \%), \mathrm{FeSO}_{4} \cdot 7 \mathrm{H}_{2} \mathrm{O}, \mathrm{HCl}$ and $\mathrm{NaOH}$ are analytically pure , KQ - $250 \mathrm{db}$ numerical controlled ultrasonic cleaning machine (kunshan ultrasonic instruments co., LTD.) UV-3 series ultraviolet visible light spectrophotometer (Shanghai United States of Instrument Co., Ltd.), Analytical balance, PH (PHS-3C).

Experiental method. Select phenol as the research object, the mixed water containing phenol 10 $\mathrm{mg} / \mathrm{L}$ phenol solution, study on the treatment of phenol water samples by ultrasonic, hydrogen peroxide, Fenton reagent, oxidation treatment technology and combined technology .

Analytical method. For the quantitative analysis of the content of phenol in water samples by 4-Aminoantipyrine direct spectrophotometric method ${ }^{[1]}$

\section{Results and discussion}

The influence of ultrasonic power on phenol degradation rate. At room temperature, with different ultrasonic power handling phenol solution for 2 hours, degradation effects are shown in Figure 1. 


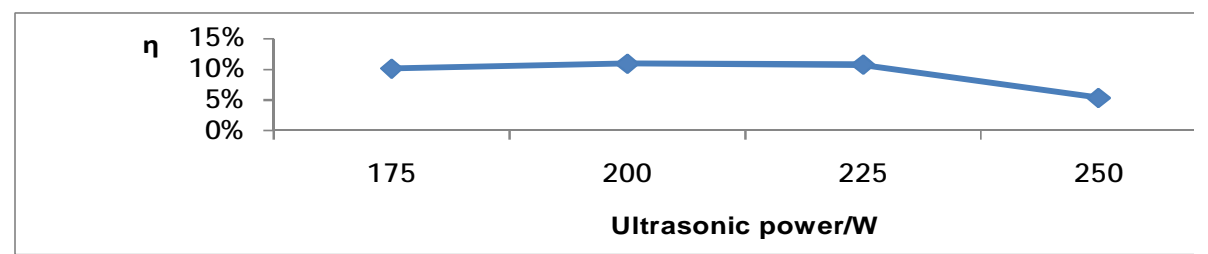

Figure 1. The influence of ultrasonic power on phenol degradation

From figure 1, we can see that, the phenol degradation rate was low by ultrasonic treatment alone, the degradation rate of phenol in water samples, along with the increase of ultrasonic power, has a first increase and then decreased. When the ultrasonic output power was $200 \mathrm{~W}$, the phenol degradation rate was the maximum, $10.9 \%$. The results of this experiment results consistent with Tang Hongyan et al. That is, when the ultrasonic frequency is constant, ultrasonic intensity, ultrasonic cavitation effect is also enhanced, the rate of ultrasonic degradation of the reaction is also increased,but when the ultrasonic intensity increases to a large, the generated cavitation bubble can be long enough without enough time to collapse, and sound energy is too great, cavitation bubble will be formed in the negative phase of sound waves grow big block, on the contrary make system can use the sound field of energy is reduced, the degradation efficiency decline ${ }^{[2]}$.

Effect of $\mathrm{H}_{2} \mathrm{O}_{2}$ on the degradation rate of phenol. The influence of $\mathrm{pH}$ value for phenol degradation rate. Configuration $10 \mathrm{mg} / \mathrm{L}$ phenol solution $200 \mathrm{~mL}$, the measured $\mathrm{pH}$ value is 6.6 , weak acid, the $\mathrm{pH}$ value of the solution is controlled using $\mathrm{HCl}$ and $\mathrm{NaOH}$,treatment of phenol solution with $\mathrm{H}_{2} \mathrm{O}_{2} 5 \mathrm{~mL} / \mathrm{L}$ for 1 hours, degradation effects are shown in Figure 2

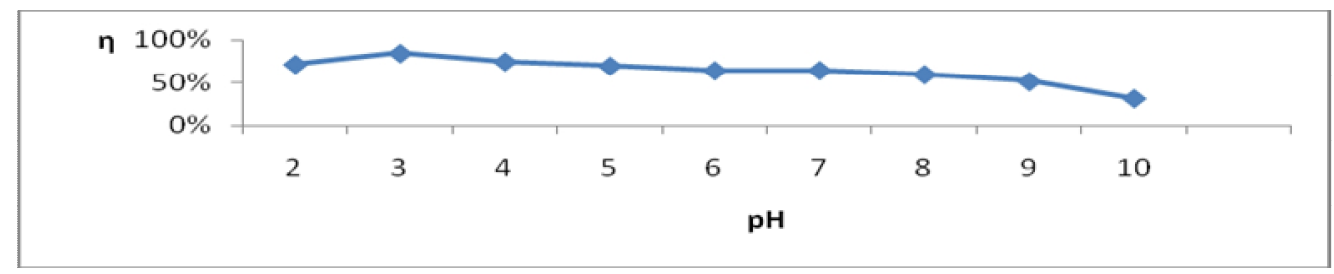

Fig. 2 Effect of $\mathrm{pH}$ value on the degradation rate of phenol by $\mathrm{H}_{2} \mathrm{O}_{2}$

From Figure 2, the $\mathrm{H}_{2} \mathrm{O}_{2}$ process was found to be suitable for the treatment of phenol under acidic conditions, the best $\mathrm{pH}$ was 3 , the degradation effect was best, $84.8 \%$, the degradation rate increased with the increase of the initial solution $\mathrm{pH}$ value at the optimum $\mathrm{pH}(\mathrm{pH}=3)$, the phenol degradation rate decreased with the increase of $\mathrm{pH}$ value after the initial solution $\mathrm{pH}$ value was greater than 3 , alkaline condition is not conducive to the degradation of phenol by $\mathrm{H}_{2} \mathrm{O}_{2}$, This is because ${ }^{[3]}$ the initial $\mathrm{pH}$ value of the solution will affect the existence of phenol, under acidic conditions, phenol exists by the form of the molecule in the water, with the increase of $\mathrm{pH}$ value, the solution of $\mathrm{OH}^{-}$is increasing, weak acid phenol will react with $\mathrm{OH}^{-}$, in ionic form exists in solution ,

Treatment of phenol solution with different concentrations of hydrogen peroxide. $10 \mathrm{mg} / \mathrm{L}$ phenol solution $(1000 \mathrm{~mL})$ was treated with hydrogen peroxide for 2 hours. Hydrogen peroxide was 1 , 2, 3, 4, 5mL/L, and the degradation results were shown in Figure 3.

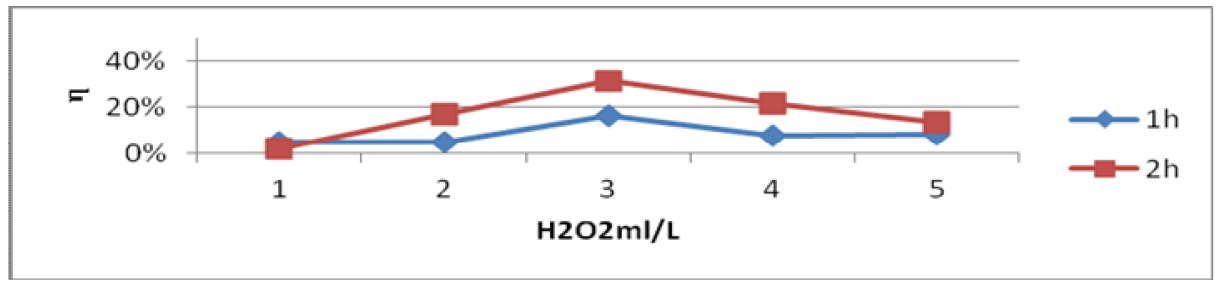

Fig. 3 Effect of different concentrations of hydrogen peroxide on the degradation of phenol solution

We can see from Figure 3 , with the increase of the amount of hydrogen peroxide, the degradation rate of phenol increased firstly and then decreased, in this experiment, When $10 \mathrm{mg} / \mathrm{L}$ phenol solution 
was added to $3 \mathrm{~mL} / \mathrm{L}$ hydrogen peroxide, the rate of phenol decreased by 2 hours and the maximum value was $31.1 \%$. This is because ${ }^{[2]}$, Hydrogen peroxide is both the generation of $\bullet \mathrm{OH}$ agent and $\bullet \mathrm{OH}$ scavenger, when hydrogen peroxide concentration in solution is relatively small, with the increase of the amount of the added amount, the absolute quantity of the decomposition is increased, produce more $\bullet \mathrm{OH}$, accelerate the degradation rate of phenol, but when the concentration of hydrogen peroxide in solution is too large, hydrogen peroxide as a scavenger of $\bullet \mathrm{OH}$, not only consumes $\mathrm{OH}$, but also causes the invalid decomposition of hydrogen peroxide, and reduces the actual utilization rate of hydrogen peroxide, Leading to hydrogen peroxide dosing amount reaches a certain value, the phenol degradation rate declines. So, the actual water treatment in hydrogen peroxide optimal dosing quantity need according to the actual situation.

Fenton reagent effect on the degradation of phenol water samples $\cdot \mathrm{H}_{2} \mathrm{O}_{2}$ and $\mathrm{Fe}^{2+}$ has important impact on turnover ratio on the $\bullet \mathrm{OH}$, when hydrogen peroxide dosage is large, lead to waste of $\bullet \mathrm{OH}$, If the catalyst $\mathrm{Fe}^{2+}$ turnover is relatively high, is that generates hydrogen peroxide, $\bullet \mathrm{OH}$ too fast, make too late to react with the matrix of $\bullet \mathrm{OH}$ concentration produces water, wasteful, and an excess of $\mathrm{Fe}^{2+}$ make the shade of the aqueous solution increases ${ }^{[4]}$, so the good control of $\mathrm{H}_{2} \mathrm{O}_{2}$ and $\mathrm{Fe}^{2}$ + than in actual engineering is very important.

Change the ferrous sulphate and hydrogen peroxide dosage, to find the best dosage ratio, concentration of $10 \mathrm{mg} / \mathrm{L}$ phenol solution, Join different $\mathrm{Fe}_{2} \mathrm{SO}_{4} \cdot 7 \mathrm{H}_{2} \mathrm{O}$ and the amount of $\mathrm{H}_{2} \mathrm{O}_{2}, 2 \mathrm{~h}$ reaction, the determination results as shown in figure 4.

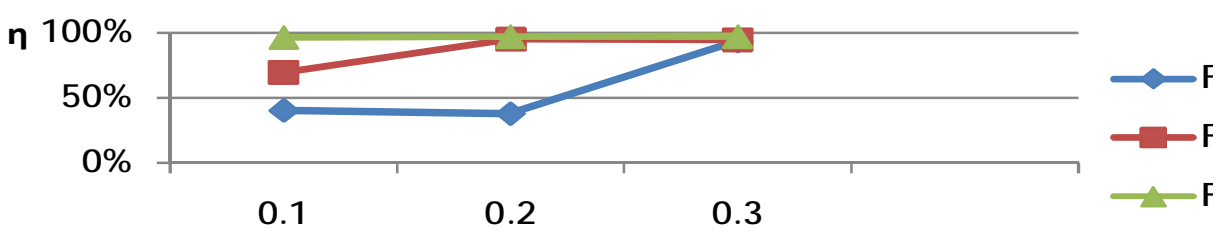

Figure 4 Different volumes than the degradation effect

As can be seen from the figure 4 processing $10 \mathrm{mg} / \mathrm{L}$ water containing phenol, response for two hours, ferrous sulfate $5 \mathrm{mg} / \mathrm{L}$, hydrogen peroxide $0.3 \mathrm{~mL} / \mathrm{L}$ and ferrous sulfate $8 \mathrm{mg} / \mathrm{L}$, hydrogen peroxide $0.2 \mathrm{~mL} / \mathrm{L}$, phenol removal rate can reach more than $95 \%$, drinking water chromaticity into consideration, Recommended ferrous ion $5 \mathrm{mg} / \mathrm{L}$, hydrogen peroxide $0.3 \mathrm{~mL} / \mathrm{L}, \mathrm{FeSO}_{4} .7 \mathrm{H}_{2} \mathrm{O}$ and $\mathrm{H}_{2} \mathrm{O}_{2}$, the quality of the best ratio of 1:20.

Ultrasound with fenton reagent processing phenol water samples. Configuration $500 \mathrm{ml} 20$ $\mathrm{mg} / \mathrm{L}$ phenol solution, Add ferrous $5 \mathrm{mg}$, join the $\mathrm{H}_{2} \mathrm{O}_{2} 0.2 \mathrm{ml}, 0.3 \mathrm{ml}$ respectively, ultrasonic coordination treatment compared with the individual treatment of fenton reagent, the relation between phenol degradation rate changes over time, the result is shown in figure 5.

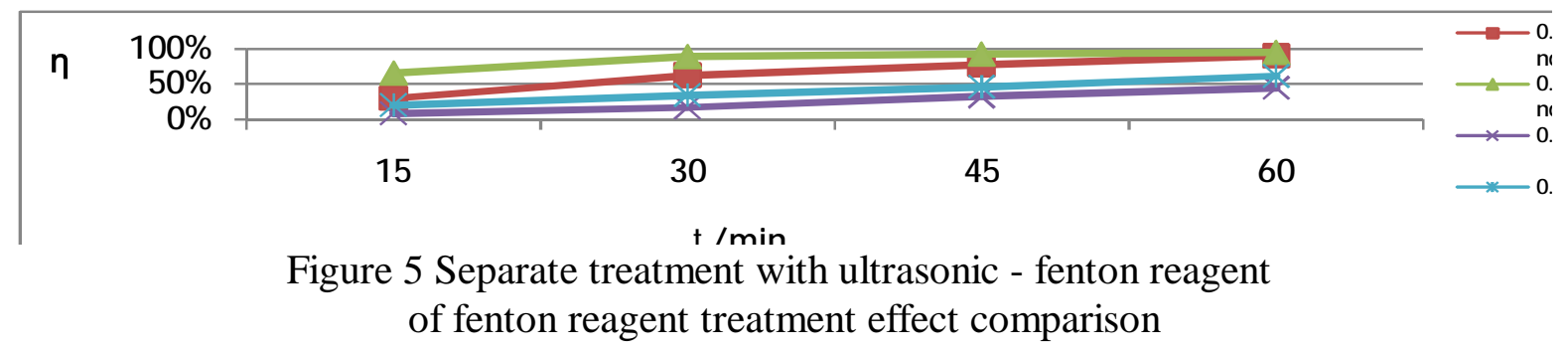

As can be seen from the figure 5, used in combination with ultrasonic and fenton reagent, speed up the processing speed of the phenol, Improve the degradation rate, ultrasound and fenton reagent have synergy in the treatment of the phenol solution.

Different initial concentration of the degradation effect. Further study on the synergy of ultrasonic and fenton reagent degradation of phenol, deal with different concentrations of phenol with 
fenton reagent solution, errousion $5 \mathrm{mg} / \mathrm{L}$, hydrogen peroxide $0.1 \mathrm{~mL} / \mathrm{L}$ experiment result is shown in figure 6 .

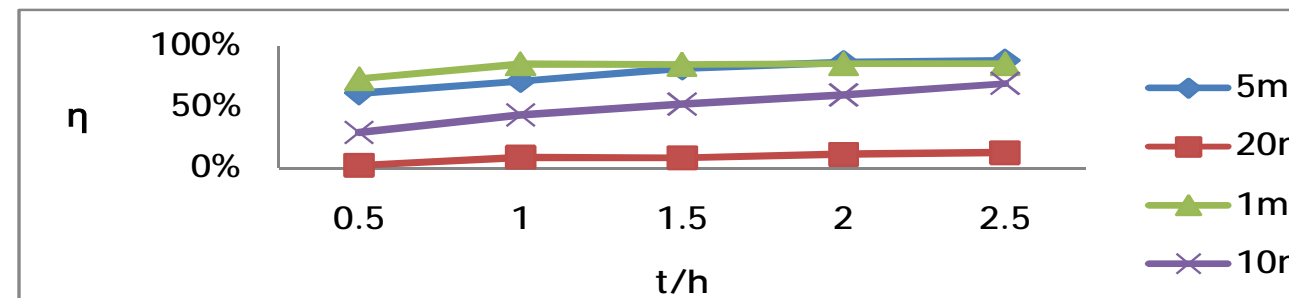

Figure 6 Different initial concentration of the degradation effect

With the same amount of fenton reagent degradation of different concentrations of phenol solution, with various concentrations of phenol degradation rate increased with the extension of processing time, but the lower the initial concentration of phenol, the degradation efficiency is high, and the maximum removal rate in a relatively short time. Such as the concentration of $1 \mathrm{mg} / \mathrm{L}$ of phenol, response 1 hour and degradation rate has reached $85 \%$, while the concentration of $20 \mathrm{mg} / \mathrm{L}$ of phenol, 2.5 hours response degradation rate of only $12.76 \%$. Therefore, for different concentrations of phenol water samples need to add how much fenton reagent and reaction to determine how long should be through experiments.

\section{Summary}

$\mathrm{H}_{2} \mathrm{O}_{2}$ treatment of phenol is appropriate under acid condition, optimum $\mathrm{pH}$ is 3 , with increasing amounts of hydrogen peroxide inputs, Phenol degradation rate showed a trend of decrease after the first increases, so, there is a best dosage of hydrogen peroxide value, the actual water treatment in hydrogen peroxide optimal dosing quantity need according to the actual situation, used in combination with ultrasonic and fenton reagent, accelerate the processing rate of phenol and improve the degradation rate, Ultrasound and fenton reagent have synergy in the treatment of the phenol solution. Using ultrasound alone, hydrogen peroxide degradation of phenol in water, degradation effects are more bad, using fenton reagent degradation effect is better,fenton reagent with a combined use of ultrasonic degradation effect is best.

\section{Acknowledgements}

The national water pollution control and management of science and technology major projects zx07404 (2012-2012)

\section{References}

[1] The state environmental protection administration of water and wastewater monitoring method editorial board. Water and wastewater monitoring analysis method (4th edition) [M]. Beijing: China environmental science press, 2002, 12:460-462.

[2] Shang Gongyan, Luo Yatian, Lin. The research of ultrasonic degradation of phenol solution [J]. Environmental technology, 2004,05:16-18.

[3] zuo-ming zhou, guo-hua jing. US/Fenton co-treating phenol simulation wastewater [J]. Environmental science and management, 2006, 12:102-104.

[4] zhi-zhong xu, Barbara li. Factors affecting hydrogen peroxide decomposition analysis [J]. Dyeing and finishing technology, 2006,01:33-35. 